\title{
A comparative study of efficacy and safety of anti-oxidants as an add-on therapy to metformin on glycemic parameters in newly diagnosed type 2 diabetes mellitus patients at a tertiary care hospital
}

\author{
Yashaswini P. ${ }^{1}$, Geetha A. ${ }^{2 *}$, Ravi K. ${ }^{3}$ \\ ${ }^{1}$ Department of Pharmacology, Sapthagiri Institute of Medical Sciences and Research Centre, Bengaluru, Karnataka, \\ India \\ ${ }^{2}$ Department of Pharmacology, ${ }^{3}$ Department of Medicine, Bangalore Medical College and Research Institute, \\ Bengaluru, Karnataka, India
}

Received: 14 June 2021

Accepted: 06 July 2021

*Correspondence:

Dr. Geetha A.,

Email: geetha25bmcri@gmail.com

Copyright: (C) the author(s), publisher and licensee Medip Academy. This is an open-access article distributed under the terms of the Creative Commons Attribution Non-Commercial License, which permits unrestricted non-commercial use, distribution, and reproduction in any medium, provided the original work is properly cited.

\begin{abstract}
Background: Oxidative stress plays major role in diabetes mellitus (DM), abnormal high free radicals decline antioxidant defence mechanism can lead to damage of cellular organelles and enzymes, increased lipid peroxidation and insulin resistance leads to development of complications. Supplementation of antioxidants protects free radical induced damage and further complications. The objective was to evaluate the efficacy and safety of metformin versus metformin with vitamin $\mathrm{C}$ and $\mathrm{E}$ on glycaemic parameters in newly diagnosed type 2 diabetes mellitus (T2DM).

Methods: 60 newly diagnosed T2DM patients were randomized into two groups of 30 in each to receive metformin (500 mg BD) alone in group A versus metformin (500 mg BD)+vitamin C (500 mg OD)+vitamin E (400 mg OD) in group B for 12 weeks. Efficacy was measured by improvement in glycaemic (FBS fasting blood sugar, PPBS postprandial blood sugar and HbA1c glycosylated haemoglobin) parameters at week 4, 8 and 12 from baseline. Safety was assessed by monitoring treatment emergent adverse effects.

Results: The baseline characteristics were comparable between the two groups. There was a significant reduction of glycaemic parameters seen in both the groups from baseline to week $12(\mathrm{p}<0.001)$ but the difference was not statistically significant between the two groups ( $p>0.05)$. No significant adverse effects were noted.

Conclusions: Both the groups are effective in improving glycaemic indices and supplementation of vitamins along with metformin as compared to metformin alone with no significant adverse effect. Hence, daily consumption of vitamins may be beneficial in decreasing blood glucose in patients with T2DM and thus reducing the risk of complications.
\end{abstract}

Keywords: Diabetes mellitus, Oxidative stress, Metformin, Vitamin C, Vitamin E

\section{INTRODUCTION}

DM is a chronic metabolic disorder characterised by a high blood glucose concentration-hyperglycaemia caused by insulin deficiency, often combined with insulin resistance. ${ }^{1}$ According to International diabetic federation atlas 2017, 425 million people were suffering with DM globally and 69.2 million in India. ${ }^{2}$

Metformin is currently the most commonly used oral agent to treat T2DM and is generally accepted as the first-line 
treatment for this condition. Metformin lowers blood glucose by reducing hepatic glucose production and increasing peripheral glucose uptake. ${ }^{3}$

The gradual increase in free radicals and diminishing antioxidant defence mechanism potential is also the fact linking DM with oxidative stress. Oxidative stress is defined as excess formation and/or insufficient removal of highly reactive molecules such as reactive oxygen species (ROS) and reactive nitrogen species (RNS). ${ }^{4}$

Antioxidants are chemical or biological agents able to neutralize the potentially damaging action of free radicals such as unstable molecules like peroxyl radical, hydroxyl radical, singlet oxygen and peroxynitrate radicals. ${ }^{5}$

Vitamin E and vitamin C effectively scavenges the free radicals in cell membranes, thereby inhibiting lipid peroxidation and terminates the free radical induced peroxidation of lipid membrane. ${ }^{6}$ In addition, vitamin C has been shown to decrease blood glucose, plasma cholesterol and triglycerides in T2DM patients. ${ }^{7}$

However, there has been limited clinical data regarding efficacy of antioxidant property of vitamin $\mathrm{E}$ and $\mathrm{C}$ on glycaemic parameters in T2DM. Thus, more studies are needed before it is recommended as a routine treatment for diabetic patients.

\section{Objective}

The objective was to evaluate the efficacy and safety of metformin versus metformin with vitamin $\mathrm{C}$ and $\mathrm{E}$ on glycaemic parameters in newly diagnosed T2DM.

\section{METHODS}

A randomized, prospective, comparative study conducted between November 2016 to May 2018 in the outpatient department of medicine, Victoria and Bowring hospitals, attached to Bangalore Medical College and Research Institute (BMCRI), Bengaluru. Patients willing to give written informed consent, aged 18-60 years of either sex, newly diagnosed T2DM (as per ADA guidelines of 2016) were included in the study.

Patients with T1DM, cardiac disease, liver disease, renal disease, malignancy, haematological disorders, patients with diabetic ketoacidosis, complication of diabetes, patients on lipid lowering drugs or who received vitamin $\mathrm{C}$ and $\mathrm{E}$ or any other antioxidant over last three months, smokers and alcohol patients, allergic to study medication and pregnant and lactating mothers were excluded from the study.

After obtaining institutional ethics committee clearance and written informed consent, the outpatients in the department of medicine fulfilling the inclusion and exclusion criteria were enrolled in the study. 60 study subjects will be randomly assigned into two groups of 30 patients in each group and randomized in a 1:1 ratio using computer random sequence generator (www.randomization.com) to receive either tablet metformin $500 \mathrm{mg}$ (BD) $(\mathrm{N}=30)$ orally with food in group $\mathrm{A}$ and tablet metformin $500 \mathrm{mg}$ (BD) with food and capsule vitamin E $400 \mathrm{mg}$ (OD) and tablet vitamin C 500 $\mathrm{mg}(\mathrm{OD})(\mathrm{N}=30)$ orally after breakfast in group $\mathrm{B}$.

Demographic data, medical history, co-morbid conditions, physical examination, vital signs, relevant laboratory investigations were done at baseline, at the end of 4,8 and 12 weeks, drug prescription by the treating physician were be recorded in the study proforma. Relevant laboratory investigations were done at baseline, at the end of 4, 8 and 12 weeks. Concomitant medications that are necessary were given at the discretion of the physician and were recorded. Adverse events were recorded and graded according to severity. Medication compliance was assessed with the help of a medication compliance card and patient were said to be compliant if he takes $80 \%$ of medication.

Efficacy was assessed by attainment of glycaemic control, based on FBS, PPBS and HbA1c parameters at week 4, 8 and 12 from baseline. Safety was assessed by monitoring treatment emergent adverse effects. Global evaluation of overall tolerability by subjects was evaluated at week 12 in both the groups.

\section{Statistical analysis}

Data was collected and continuous variables were expressed as mean \pm standard deviation (parametric data). The continuous data in this study was analysed using repeated measure ANOVA (analysis of variance) for intragroup comparison and unpaired test (parametric data) for intergroup comparison. Categorical data was expressed as percentages/proportions and was analysed using Chi-square test. $\mathrm{P}$ value $<0.05$ was considered statistically significant. Statistical analyses were performed using Vassar Stats software.

\section{RESULTS}

Sixty six patients were screened for inclusion in the study of whom 60 patients who met the inclusion and exclusion criteria and gave written informed consent to participate in the study were enrolled in the study. Patients were randomised either to the metformin arm (group $\mathrm{A}$ ) or metformin+vitamin C+vitamin E arm (group B) with 30 patients in each of the arms for a duration of 12 weeks. Table 1 represents the demographic profile of the patients included in the study. Both the treatment groups were matched with respect to baseline demographic characteristics.

The age range of patients with DM was between 18 to 60 years. The mean age was $48.33 \pm 5.80$ years in group $\mathrm{A}$ and $46.43 \pm 7.74$ years in the group $B(p=0.20) .86 \%$ and $70 \%$ 
of patients belonged to be age group of 41-60 in group A and group B, respectively.
Both the study groups were gender matched. There were $50 \%$ male and 50\% female patients in the group A and $40 \%$ male and $60 \%$ female patients in the group $B(p=0.60)$.

Table 1: Baseline characteristics.

\begin{tabular}{|c|c|c|c|c|}
\hline Parameters & & $\begin{array}{l}\text { Group A tablet } \\
\text { metformin } 500 \text { mg/day } \\
\mathbf{N}=\mathbf{3 0}(\%)\end{array}$ & $\begin{array}{l}\text { Group B tablet metformin } \\
500 \text { mg/day+tablet } \\
\text { vitamin C } 500 \\
\text { mg/day+capsule vitamin } \\
\text { E } 400 \text { mg/day } N=30(\%)\end{array}$ & $P$ value \\
\hline \multirow{2}{*}{ Age (in years) } & $18-40$ & $4(14)$ & $9(30)$ & \multirow{2}{*}{$0.20 \dagger$} \\
\hline & $41-60$ & $26(86)$ & $21(70)$ & \\
\hline \multirow{2}{*}{ Gender } & Male & $15(50)$ & $12(40)$ & \multirow{2}{*}{$0.60 *$} \\
\hline & Female & $15(50)$ & $18(60)$ & \\
\hline \multirow{2}{*}{ Family history of DM } & Present & $20(67)$ & $17(57)$ & \multirow{2}{*}{$0.59 *$} \\
\hline & Absent & $10(33)$ & $13(43)$ & \\
\hline \multirow{4}{*}{ Weight (in kgs) } & $50-60$ & $5(17)$ & $5(17)$ & \multirow{4}{*}{$0.39 \dagger$} \\
\hline & $61-70$ & $10(33)$ & $16(53)$ & \\
\hline & $71-80$ & $12(40)$ & $8(27)$ & \\
\hline & $81-90$ & $3(10)$ & $1(3)$ & \\
\hline \multirow{2}{*}{$\begin{array}{l}\text { Hypertension } \\
\text { associated with T2DM }\end{array}$} & Present & $20(67)$ & $13(43)$ & \multirow{2}{*}{$0.11 *$} \\
\hline & Absent & $10(33)$ & $17(57)$ & \\
\hline
\end{tabular}

$\dagger$ Data analysed using Fisher exact test; *data analysed using Chi-square, $p<0.05$ is considered statistically significant, T2DM: type 2 diabetes mellitus.

Table 2: Baseline glycaemic parameters.

\begin{tabular}{|llll|}
\hline Parameters & Group A $($ mean \pm SD) mg/dl & Group B $($ mean \pm SD) mg/dl & P value \\
\hline FBS & $168.83 \pm 15.61$ & $163.66 \pm 11.78$ & $0.15^{*}$ \\
\hline PPBS & $260.16 \pm 22.66$ & $249.03 \pm 25.22$ & $0.07^{*}$ \\
\hline HbA1c & $7.42 \pm 0.54$ & $7.19 \pm 0.49$ & $0.10^{*}$ \\
\hline
\end{tabular}

*Data analysed by unpaired t test, $\mathrm{p}<0.05$ is considered statistically significant.

Table 3: Mean reduction of HbA1c from baseline to week 12 within group.

\begin{tabular}{|llll|}
\hline HbA1c & Baseline $($ mean \pm SD) $\mathrm{mg} / \mathrm{dl}$ & Week $12(\mathrm{mean} \pm \mathrm{SD})$ mg/dl & P value \\
\hline Group A & $7.42 \pm 0.54$ & $7.19 \pm 0.49$ & $<0.0001 * \dagger$ \\
\hline Group B & $6.99 \pm 0.60$ & $6.81 \pm 0.51$ & $<0.0001 * \dagger$ \\
\hline
\end{tabular}

*Data analysed by paired t test, $\uparrow \mathrm{p}<0.05$ considered statistically significant.

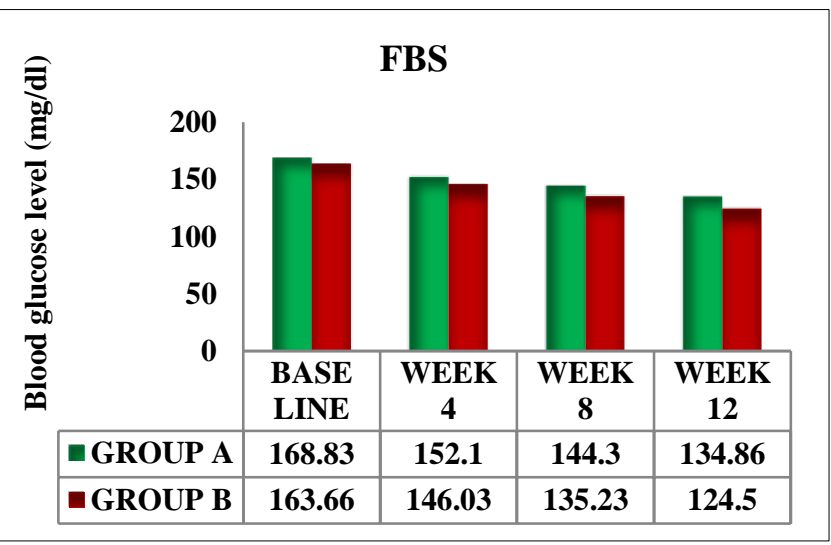

Figure 1: Mean reduction of FBS at follow up visits in both the group.

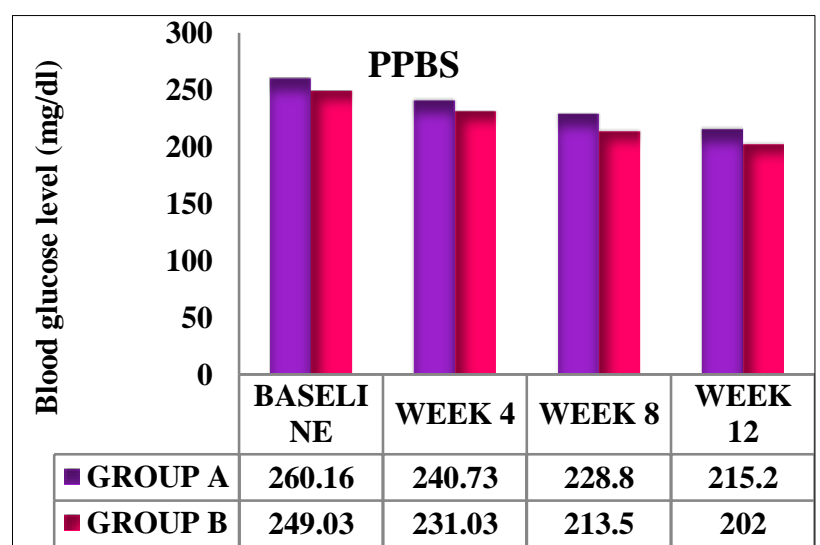

Figure 2: Mean reduction of PPBS at follow up visits in both the group. 


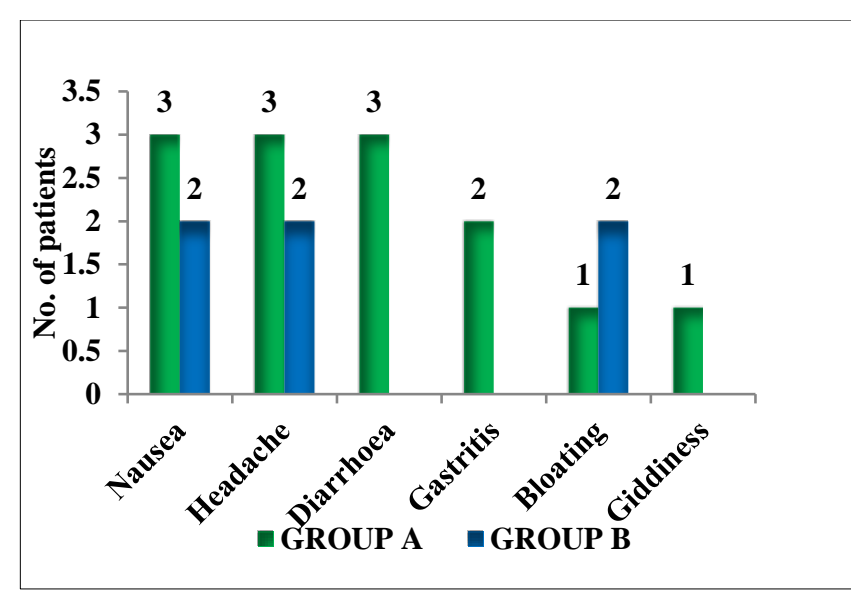

Figure 3: Adverse effects.

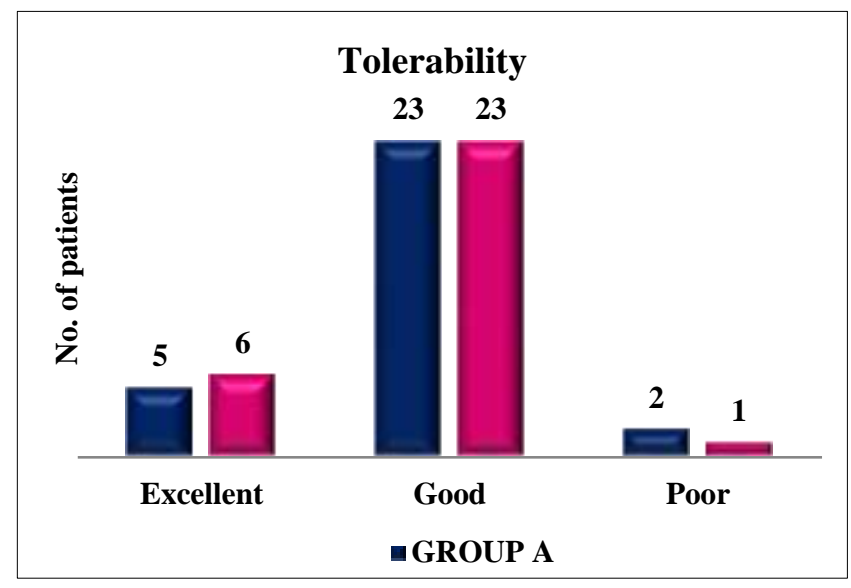

Figure 4: Global evaluation of tolerability in both the groups.

There were $67 \%$ of patients had family history of DM in the group A and $57 \%$ of the patient had family history of $\mathrm{DM}$ in the group B $(\mathrm{p}=0.59)$.

In the group A, $67 \%$ of patients had history of hypertension and in the group B, $43 \%$ of patients had history of hypertension associated with newly diagnosed T2DM patients.

Table 2 shows baseline glycaemic parameters at baseline in both group A and group B, both the groups were comparable with respect to glycaemic parameters at baseline.

The mean FBS at 4 weeks of treatment was $152.1 \pm 17.16$ and $146.03 \pm 13.65$ in the group A and group B respectively and at 8 weeks of treatment it was $144.3 \pm 18.06$ and $135.23 \pm 17.88$ in the group A and group B respectively which was statistically non-significant $(p>0.05)$. Mean PPBS at 4 weeks treatment $240.73 \pm 26.10$ and $231.03 \pm 32.87$ in group A and group B respectively and at 8 weeks of treatment it was $228.8 \pm 30.78$ and $213.5 \pm 38.91$ in group A and group B respectively which was statistically non-significant $(\mathrm{p}>0.05)$.
The mean FBS and PPBS after 12 weeks of treatment was $134.86 \pm 19.21$ and $215.2 \pm 48.46$ in the group $A$ and $124.5 \pm 20.94$ and $202 \pm 36.38$ in the group B, respectively. Both the groups effectively reduced FBS and PPBS compared to baseline $(p<0.0001)$ at the end of 12 weeks. Figure 1 and 2 represents the mean FBS and PPBS in both groups at baseline and at each follow up visits respectively.

Table 3 represents mean reduction of $\mathrm{HbA} 1 \mathrm{c}$ from baseline to week 12 in both group $A$ and group B, there is statistically significant $(\mathrm{p}<0.0001)$ reduction of $\mathrm{HbA1c}$ from baseline to week 12 within the group in both group A and group B, respectively.

The treatment was well tolerated in both the groups. The adverse effects encountered were mild to moderate in nature, no serious adverse events were noted. None of the adverse effect warranted discontinuation of study medication. Figure 3 shows the various adverse effects encountered in both the groups.

Figure 4 represents the global evaluation of tolerability in the metformin and metformin+vitamin E+vitamin $\mathrm{C}$ groups. The percentage of patients compliant to study medications was $100 \%$ in both the groups.

\section{DISCUSSION}

The present study was designed to compare the efficacy and safety of metformin alone versus supplementation of vitamin $\mathrm{C}$ and vitamin $\mathrm{E}$ along with metformin on FBS, PPBS and HbA1c among newly diagnosed T2DM patients in tertiary care hospital.

Based on the experimental protocol, the participants were divided into two groups, the first group (group A) treated with tablet metformin $500 \mathrm{mg}$ BD without any vitamin supplementation $(\mathrm{N}=30)$. The second group (group $\mathrm{B}$ ) was treated with tablet metformin $500 \mathrm{mg}$ BD supplemented with tablet vitamin C $500 \mathrm{mg}$ OD and capsule vitamin E $400 \mathrm{mg}$ OD $(\mathrm{N}=30)$. Both the groups were followed up monthly for three months.

Our findings suggested that there was no significant difference in glycaemic parameters in between the groups by the end of the study. There was no significant difference in the adverse effect profile in both the groups.

In our study, fasting blood sugar was $168.83 \pm 15.6 \mathrm{mg} / \mathrm{dl}$ at the baseline and decreased to $134.86 \pm 19.21 \mathrm{mg} / \mathrm{dl}$ at week 12 in group A and it was $163.66 \pm 11.78 \mathrm{mg} / \mathrm{dl}$ at baseline and reduced to $124.5 \pm 20.94 \mathrm{mg} / \mathrm{dl}$ at week 12 in group B. In both the groups there is significant reduction of FBS from baseline to week 12 . But there is no significant difference in between the groups.

PPBS reduced from $260.16 \pm 22.66 \mathrm{mg} / \mathrm{dl}$ to $215.2 \pm 48.46$ $\mathrm{mg} / \mathrm{dl}$ in group A and reduced from $249.03 \pm 25.22$ to $202 \pm 36.38$ in group B from baseline to week 12 respectively, which showed significant difference in PPBS 
from baseline to week 12 in both the groups. But there was no significant difference in between the groups.

$\mathrm{HbA} 1 \mathrm{c}$ reduced from $7.42 \pm 0.54 \mathrm{mg} / \mathrm{dl}$ to $7.19 \pm 0.49 \mathrm{mg} / \mathrm{dl}$ in group A and it was reduced from $6.99 \pm 0.60 \mathrm{mg} / \mathrm{dl}$ to $6.81 \pm 0.51 \mathrm{mg} / \mathrm{dl}$ in group B from baseline to week 12, reduction of $\mathrm{HbA1c}$ in both the groups were statistically significant. But there was no significant difference in between the groups. Statistically significant difference was noted in glycaemic parameters within the groups from baseline to week 12, but there was no difference in glycaemic parameters between the groups.

In a study conducted by El-Aal et al in 2018 with T2DM patients and 10 in each group of aged between 40-60 years, one group treated with metformin alone and another group treated with vitamin C (500 mg BD) and vitamin E (400 $\mathrm{mg} \mathrm{BD}$ ) along with metformin (500 $\mathrm{mg} \mathrm{BD}$ ) for three months. ${ }^{8}$ Among glycaemic parameters they estimated only FBS and HbA1c levels and FBS decreased from $162.26 \pm 26$ to $133.05 \pm 2.42 \mathrm{mg} / \mathrm{dl}$ and $\mathrm{HbA} 1 \mathrm{c}$ from $8.77 \pm 0.47$ to $7.72 \pm 0.35 \mathrm{mg} / \mathrm{dl}$ from baseline to week 12 respectively in the supplemented group, results of this group match with our study. But in their study metformin alone received group shows increase in FBS and HbA1c by the end of 12th week, it was different from our study results it could be due to inadequate sample size (10 in each group) of their study.

Another study conducted by Hamed et al in 2015, a nonrandomized prospective controlled trail in T2DM patients and 20 patients in each group, one group treated with metformin alone and another group treated with vitamin $\mathrm{C}$ (1000 mg OD) and vitamin E (800 mg OD) along with metformin for three months. ${ }^{9}$ Among glycaemic parameters they found significant decrease in both FBS and HbA1c from baseline to week 12 in group supplemented with vitamin $\mathrm{C}$ and $\mathrm{E}$, FBS reduced from $159.15 \pm 30.05$ to $122.94 \pm 23.78 \mathrm{mg} / \mathrm{dl}$ and $\mathrm{HbA} 1 \mathrm{c}$ from $7.32 \pm 0.55$ to $6.12 \pm 0.50 \mathrm{mg} / \mathrm{dl}$ from baseline to week 12 respectively. Significant reduction in FBS and HbA1c seen only in vitamin supplemented group. Our study results slightly different from this study, where we got significant reduction of glycaemic parameters in both the groups. Sample size is 20 in each group this could be the reason for varied results in FBS among metformin alone treated group.

In another study done by Gillani et al in 2017, on combined effect of metformin with vitamin C $500 \mathrm{mg} /$ day versus metformin with placebo in newly diagnosed T2DM patients and followed up for 12 months. ${ }^{10}$ FBS reduced from $7.65 \pm 2.52$ to $5.18 \pm 1.66 \mathrm{mmol} / \mathrm{l}$ and $\mathrm{HbA} 1 \mathrm{c}$ reduced from $8.83 \pm 2.41$ to $6.45 \pm 1.21 \mathrm{mg} / \mathrm{dl}$ from baseline to 12 th month when compared to placebo treated group. They got significant reduction in both FBS and HbA1c in vitamin C supplemented group could be due to long term administration (48 weeks), these results are matching with our group B results.
A study conducted by Dakhale et al in 2011, included 70 T2DM patients (35 in each group) who were already on metformin for 0-6 months and they were divided into two groups randomly, supplemented vitamin C (500 mg BD) to one group and placebo to another group and followed up for 12 weeks. ${ }^{11}$ They found that plasma ascorbic acid was low in DM patients and it was reversed significantly after treatment with vitamin $\mathrm{C}$ compared to placebo. FBS and HbA1c levels showed highly significant improvement after 12 weeks of treatment with vitamin $\mathrm{C}$. FBS was $157.63 \pm 3.13$ before treatment, reduced to $141.18 \pm 3.81$ $\mathrm{mg} / \mathrm{dl}$ after treatment, PPBS was $222.24 \pm 3.16$ before treatment, reduced to $206.69 \pm 3.31 \mathrm{mg} / \mathrm{dl}$ after treatment, $\mathrm{HbA1c}$ was $8.26 \pm 0.09$ reduced to $7.80 \pm 0.08$ after treatment in vitamin $\mathrm{C}$ treated patients which was statistically significant, this study findings were compatible with our study findings.

A study by Bhatt et al in 2012, included 65 T2DM patients of aged between 30-70 years, with minimum of 6 months ongoing oral hypoglycaemic agents treatment (metformin and/or glibenclamide). ${ }^{12}$ Patients in the intervention group received vitamin $\mathrm{C}$ (500 $\mathrm{mg}$ OD) along with oral hypoglycaemic agents, patients in control group received only oral hypoglycaemic agents for a period of 3 months. In their study in control group FBS increased from $182 \pm 46.22$ to $195.3 \pm 52.56 \mathrm{mg} / \mathrm{dl}$ and $\mathrm{HbA} 1 \mathrm{c}$ from $8.75 \pm 1.56$ to $8.92 \pm 1.65 \mathrm{mg} / \mathrm{dl}$, this is different from our study results this could be due to inclusion of patients suffering from $\mathrm{T} 2 \mathrm{DM}$ of $\geq 3$ year of duration without treatment.

A study by Rafighi et al in 2011, conducted on T2DM patients in Iran. ${ }^{13}$ One group received OHA with placebo and another group received oral hypoglycaemic agents with vitamin $\mathrm{C}+\mathrm{E}$ supplementation $(266.7 \mathrm{mg}+300 \mathrm{IU}$ each three times a day). They found highly statistically significant results with respect to FBS, HbA1c and this was almost similar to our study results and even we got statistically significant results with glycaemic parameters, for them getting highly statistically significant results could be due to higher dose of vitamin $\mathrm{C}$ and $\mathrm{E}$ administered.

In a study done by Kathore et al included 50 T2DM patients who were on oral hypoglycaemic drugs with mean duration of DM 1 to 8 years and to all 50 patients they supplemented only vitamin C (500 mg BD) for 12 weeks. ${ }^{7}$ Among glycaemic parameters they have estimated only FBS and it reduced from $146.9 \pm 36.16$ to $138.1 \pm 34.28 \mathrm{mg} / \mathrm{dl}$. Results of this study matched with our study results.

A study done by Nath et al (2013), included 46 T2DM patients who were already on treatment, to them they supplemented only vitamin C (1000 mg OD) for 8 weeks. ${ }^{14}$ FBS slightly increased from $154.58 \pm 34.54$ to $157.32 \pm 40.32 \mathrm{mg} / \mathrm{dl}$ which was different from our study results in which we got significant reduction this could be due to short duration of therapy, distinct pathophysiology and poor patient compliance. HbAlc reduced from 
$8.72 \pm 1.6$ to $7.60 \pm 1.90 \mathrm{mg} / \mathrm{dl}$ from baseline to 8 weeks which was similar to our results.

Another study done by Kuchake et al (2011), included 108 T2DM patients who were on treatment of diabetes and hypertension and they were divided into 2 groups, first group control group, second group patients received one tablet combination of antioxidant vitamin E (400 mg OD) plus vitamin C (500 mg OD) for four months. ${ }^{15} \mathrm{He}$ evaluated only $\mathrm{HbA} 1 \mathrm{c}$ parameter and it reduced from $8.7 \pm 0.04$ to $5.8 \pm 0.3 \mathrm{mg} / \mathrm{dl}$ from baseline to 4 th month which was statistically significant when compared to control group. These findings were different from our study results as we got statistically significant reduction in both the groups this difference could be due to long duration follow up of this study.

Mild adverse effects were seen in both the groups, that is, nausea, headache, diarrhoea, gastritis, bloating, giddiness and it was not statistically significant. Both the drugs were well tolerated by the patients. $43 \%$ of patients in the group A and $20 \%$ of the patients in the group B were experienced adverse effects.

In the group $\mathrm{A}$, the adverse effects were nausea (10\%), headache $(10 \%)$, diarrhoea $(10 \%)$, gastritis $(6 \%)$ and bloating $(3 \%)$. In the group $\mathrm{B}$, the adverse effects were nausea $(6 \%)$, headache $(6 \%)$ and bloating $(6 \%)$. The occurrence of adverse effects was not statistically significant between the groups $(p=0.09)$ although the incidence of overall adverse effects was greater in group A.

Supplementation of antioxidants to newly diagnosed T2DM patients might improve endogenous antioxidant capacity due to reducing blood glucose and they may play a role in preventing complications in T2DM. Since vitamin $\mathrm{E}$ and $\mathrm{C}$ are exogenous antioxidants that are not associated with toxicity at recommended dosage, supplementing these vitamins along with regular antidiabetic drugs should be considered.

\section{CONCLUSION}

Both the groups are effective in improving glycaemic indices and supplementation of vitamins along with metformin as compared to metformin alone with no significant adverse effect. Hence, daily consumption of vitamins may be beneficial in decreasing blood glucose in patients with T2DM and thus reducing the risk of complications.

Funding: No funding sources Conflict of interest: None declared

Ethical approval: The study was approved by the Institutional Ethics Committee

\section{REFERENCES}

1. Rang HP, Dale MM, Ritter JM. The control of blood glucose and drug treatment of diabetes mellitus. Rang and Dale's pharmacology. 7th ed. Edinburgh: Elsevier/Churchill Livingstone; 2012: 378.

2. Diabetes Care. Fact sheet: Introduction: standards of medical care in diabetes-2018. Available at: http://care.diabetesjournals.org/content/41/Suppleme nt_1. Accessed on 01 June 2021.

3. Powers AC, D'Alessio D. Endocrine pancreas and pharmacotherapy of diabetes mellitus and hypoglycaemia. In: Goodman L, Goodman L, Brunton L, Lazo J, Parker K, eds. The pharmacological basis of therapeutics. 12th ed. New York: McGraw-Hill; 2011: 1258.

4. Johansen J, Harris A, Rychly D, Ergul A. Oxidative stress and the use of antioxidants in diabetes: Linking basic science to clinical practice. Cardiovas Diabetol. 2005;4(1):5.

5. Ahmad N, Rahmat A, Mushtaq A, Nadia M. Role of antioxidant in oxidative stress and diabetes mellitus. J Pharmacogn Phytochem. 2015;3(6):217-20.

6. Ayepola O, Brooks N, Oguntibeju O. Oxidative stress and diabetic complications: the role of antioxidant vitamins and flavonoids. Antioxid Antidiabet Agent Human Health. 2014:27-58.

7. Kathore VR, Bansode DG. The effect of vitamin c on fasting blood glucose level and lipid profile in type-2 diabetes mellitus patients. Int $\mathrm{J}$ Rec Trend Sci Technol. 2014;16(3):585-90.

8. El-Aal AA, El-Ghffar EAA, Ghali AA, Zughbur MR, Sirdah MM. The effect of vitamin $\mathrm{C}$ and/or $\mathrm{E}$ supplementations on type 2 diabetic adult males under metformin treatment: A single-blinded randomized controlled clinical trial. Diabetes Metab Syndr. 2018;12(4):483-9.

9. Hamed AT, Zinati SMA, Swirky AA. The effect of vitamin $\mathrm{C}$ alone or in combination with vitamin $\mathrm{E}$ on fasting blood glucose, glycosylated hemoglobin and lipid profile in type 2 diabetic patients (Gaza Strip). Jordan J Pharmaceut Sci. 2016;9(1):12-24.

10. Gillani SW, Sulaiman SAS, Abdul MIM, Baig MR. Combined effect of metformin with ascorbic acid versus acetyl salicylic acid on diabetes-related cardiovascular complication; a 12-month single blind multicenter randomized control trial. Cardiovascular Diabetol. 2017;16(1):103-16.

11. Dakhale GN, Chaudhari HV, Shrivastava M. Supplementation of vitamin $\mathrm{C}$ reduces blood glucose and improves glycosylated hemoglobin in type 2 diabetes mellitus: a randomized, double-blind study. Adv Pharmacol Sci. 2011;11:1-5.

12. Bhatt JK, Thomas $\mathrm{S}, \mathrm{Mj} \mathrm{N}$. Effect of oral supplementation of vitamin $\mathrm{C}$ on glycemic control and lipid profile in patients with type 2 diabetes mellitus. Int J Pharm Pharmaceut Sci. 2012;4(2):524-7.

13. Rafighi Z, Arab S, Yusof MR, Shiva A. The effect of vitamin $\mathrm{c}$ and $\mathrm{e}$ on lipid profile in type 2 diabetes mellitus patients. Glob J Health Sci. 2011;3(2):69-74.

14. Nath RK, Akhter M, Sarker KR, Rahman MR, Chowdhury SS, Ishrat R. Effect of vitamin C on blood glucose \& serum lipids in type 2 diabetes patients. KYAMC J. 2013;4(1):337-40. 
15. Kuchake VG, Upasani DCD. Evaluation of protective effect of antioxidant vitamins in patients with diabetic nephropathy. Asian J Pharmaceut Clinic Res. 2011;4(4):52-4.
Cite this article as: Yashaswini $\mathrm{P}$, Geetha A, Ravi K. A comparative study of efficacy and safety of anti-oxidants as an add-on therapy to metformin on glycemic parameters in newly diagnosed type 2 diabetes mellitus patients at a tertiary care hospital. Int J Basic Clin Pharmacol 2021;10:925-31. 